\title{
Association of fish intake and smoking with risk of rheumatoid arthritis and age of onset: a prospective cohort study
}

Jeffrey A. Sparks ${ }^{1,2^{*}}$ (D, Éilis J. O'Reilly ${ }^{3,4}$, Medha Barbhaiya ${ }^{5}$, Sara K. Tedeschi ${ }^{1,2}$, Susan Malspeis ${ }^{1}$, Bing Lu ${ }^{1,2}$, Walter C. Willett ${ }^{2,3,6}$, Karen H. Costenbader ${ }^{1,2}$ and Elizabeth W. Karlson ${ }^{1,2}$

\begin{abstract}
Background: Prior studies suggest that fish may be protective for rheumatoid arthritis (RA) risk perhaps through the anti-inflammatory effect of omega-3 fatty acid, but this relationship has not been clearly established. Therefore, we investigated fish intake and RA risk by serologic status, age of onset, and smoking using a prospective cohort study with large sample size, repeated measures of dietary intake, and lengthy follow-up.

Methods: We studied fish intake and RA risk among 166,013 women in two prospective cohorts, the Nurses' Health Study (NHS, 1984-2014) and NHSII (1991-2015). Fish intake was assessed using food frequency questionnaires at baseline and every 4 years. Incident RA during follow-up and serologic status were determined by medical record review. Pooled Cox regression models estimated hazard ratios (HR) and 95\% confidence intervals (CI) for RA (overall and by serologic status and age at diagnosis) for fish intake frequency. We tested for a smoking-fish interaction for RA risk.

Results: During 3,863,909 person-years of follow-up, we identified 1080 incident RA cases. Increasing fish intake was not associated with all RA ( $\geq 4$ servings/week: multivariable HR 0.93 [95\% Cl 0.67-1.28] vs. $<1$ serving/month; $p$ for trend $=0.42$ ), seropositive RA ( $p$ for trend $=0.66$ ), or seronegative RA ( $p$ for trend $=0.45$ ), but had increased risk for RA diagnosed $>55$ years old ( $p$ for trend $=0.037$ ). Among women $\leq 55$ years old, frequent fish intake (vs. infrequent) had HRs (95\%Cls) of: 0.73 (0.52-1.02) for all RA, 0.85 (0.55-1.32) for seropositive RA, and 0.55 (0.32-0.94) for seronegative RA. Ever smokers with infrequent fish intake had highly elevated risk for RA onset $\leq 55$ years (HR $2.59,95 \% \mathrm{Cl} 1.65-4.06$ ), while ever smokers with frequent fish intake had modestly elevated RA risk (HR 1.29, 95\%Cl 1.07-1.57; vs. never smokers/frequent fish intake; $p$ for smoking-fish interaction $=0.039$ ).
\end{abstract}

Conclusion: In this large prospective cohort study, we found no clear protective effect of fish or marine omega-3 fatty acid intake on RA risk, overall or by serologic status. We found that fish intake attenuated the strong association of smoking for RA diagnosed $\leq 55$ years of age, but this requires further study.

Keywords: Rheumatoid arthritis, Fish, Diet, Inflammation, Omega-3 fatty acids, Smoking, Epidemiology

\footnotetext{
* Correspondence: jsparks@bwh.harvard.edu

'Department of Medicine, Division of Rheumatology, Immunology and

Allergy, Brigham and Women's Hospital, 60 Fenwood Road, \#6016U, Boston,

MA 02115, USA

${ }^{2}$ Harvard Medical School, 25 Shattuck St, Boston, MA 02115, USA

Full list of author information is available at the end of the article
}

(c) The Author(s). 2019 Open Access This article is distributed under the terms of the Creative Commons Attribution 4.0 International License (http://creativecommons.org/licenses/by/4.0/) which permits unrestricted use, distribution, and reproduction in any medium, provided you give appropriate credit to the original author(s) and the source, provide a link to the Creative Commons license, and indicate if changes were made. The Creative Commons Public Domain Dedication waiver (http://creativecommons.org/publicdomain/zero/1.0/) applies to the data made available in this article, unless otherwise stated. 


\section{Background}

Progress continues to be made in identifying risk factors for rheumatoid arthritis (RA) [1]. Environmental factors may affect transitions from genetic risk to RA-related autoantibody development and between asymptomatic autoimmunity and clinical onset [2,3]. While smoking is an important RA risk factor, many individuals who develop RA never smoked, so other factors likely contribute [4-8]. In particular, metabolic factors such as obesity and diet may be important for earlier RA onset [9-14].

Fish intake may decrease RA risk based on the anti-inflammatory properties of omega-3 polyunsaturated fatty acids (PUFAs), such as eicosapentaenoic acid (EPA), docosahexaenoic acid (DHA), and docosapentaenoic acid (DPA) [15]. Omega-3 PUFAs may have protective biologic effects in the phases prior to the onset of clinically-apparent RA [16-18]. After RA diagnosis, fish may have beneficial effects on disease activity and pain [19-22].

The association of fish intake with RA risk has been investigated previously, some studies showing inverse associations while others had no association [23-29]. A meta-analysis of fish intake and RA risk showed a reduction in RA risk by $20-24 \%$ (statistically non-significant) for 1-3 servings of fish/week compared to less [30]. These studies may not have been able to detect a modest association of dietary factors with RA, did not have data on confounders such as smoking, or did not investigate RA phenotypes based on serostatus or age at onset. No previous study has evaluated whether fish intake and RA risk may differ based on smoking status, the strongest environmental RA risk factor.

Therefore, we investigated fish intake and RA risk using the Nurses' Health Study (NHS) and NHSII, two prospective cohort studies with lengthy follow-up and detailed dietary/covariate data. We hypothesized that increasing fish intake and marine omega-3 PUFAs would be associated with decreased RA risk, particularly earlier-onset RA or seropositive RA. We further aimed to investigate whether fish intake had a differential effect on RA by smoking status. We hypothesized that anti-inflammatory effects of fish intake may attenuate the elevated RA risk for smokers.

\section{Methods}

\section{Study population}

The NHS and NHSII are prospective cohorts of US women who were registered nurses at enrollment. The NHS enrolled 121,700 women aged $30-55$ years in 1976; the NHSII enrolled 116,670 women aged 25-42 years in 1989. In both cohorts, women answered questionnaires at baseline and every 2 years to collect data on lifestyle, family history, diet, diagnoses, and medications.
In this study, the baseline for analysis in the NHS \& NHSII were 1984 \& 1991, respectively, when a comprehensive Food Frequency Questionnaire (FFQ) was first introduced. We excluded participants who reported a diagnosis of RA or other connective tissue disease (CTD) prior to the 1984 or 1991 questionnaires and those who did not answer the baseline FFQ. A total of 76,540 women in the NHS and 89,473 women in the NHSII were included. All aspects of the study the study comply with the Declaration of Helsinki and were approved by the Partners HealthCare Institutional Review Board.

\section{Dietary assessments}

We used a semi-quantitative FFQ to measure food intake over the previous year [11,31]. The FFQ has proven validity and reproducibility compared to food diaries and recall for a spectrum of dietary/nutritional factors [32, 33]. The FFQ ranks frequency of food/beverages on a scale ranging from never or $<1 /$ month to $\geq 6$ servings/ day. Dietary intakes were assessed in the NHS in 1984, 1986, and every 4 years until 2010. In the NHSII, the FFQ was administered in 1991 and every 4 years until 2011. We used cumulative average intake to reflect long-term consumption and to reduce measurement error. For each questionnaire cycle evaluating RA risk, cumulative average intake was calculated by averaging the repeated dietary measure from baseline until that cycle. The cumulative average intake variable was time-varying such that all available dietary measures at each time point were taken into consideration to predict RA risk in the subsequent questionnaire cycle. For example, only the fish intake measured at baseline in 1984 was considered for RA risk in the window of 1984 to 1986 in the NHS since no previous measures were available at that time point. However, a total of 8 dietary measures were used for cumulative average variable on the 2012 questionnaire cycle assessing for RA risk between 2012 and 2014. We did not analyze simple updated time-varying exposures since short-term dietary changes are less likely to impact chronic disease risk than long-term dietary habits. For categorical variables, the cumulative average intake was calculated as a continuous measure prior to categorization.

Our primary exposure was fish intake frequency. The FFQ included four items related to fish intake: 1) dark meat fish (mackerel, salmon, sardines, bluefish, or swordfish, $3-5 \mathrm{oz} ; 84-140 \mathrm{~g})$; 2) canned tuna (3-4 oz; $84-112 \mathrm{~g}$ ); 3) other fish (3-5 oz; 84-140 g); and 4) shrimp, lobster, or scallops as main dish. One fish item was added in the 1994 \& 1998 FFQs: breaded fish cakes, pieces, or fish sticks (1 serving). We calculated the servings of total fish consumed at each questionnaire cycle. As the primary exposure, we considered five categories 
for total fish intake frequency: none to $<1 /$ month, $1 /$ month to $<1 /$ week, 1 to $<2.5 /$ week, 2.5 to $<4 /$ week, and $\geq 4 /$ week. We chose these categories based on recommendations of fish intake and their use in previous reports investigating the association of fish intake with chronic disease risk [34, 35]. To investigate a threshold effect of fish intake on RA risk, we dichotomized this variable into infrequent (none to $<1 /$ month) and frequent fish intake ( $\geq 1 /$ month).

To investigate the effect of nutrients on RA risk, we analyzed the effect of marine omega-3 PUFAs intake. We considered marine omega-3 PUFAs as the sum of EPA, DHA, and DPA from diet and supplements. We did not consider these PUFAs separately since high correlation limited assessment of their independent effects. We calculated the total marine omega-3 PUFAs in each cycle as previously described [36]. Since there are no clear cutpoints for omega-3 PUFAs and RA risk, we analyzed quartiles of marine omega-3 PUFA intake.

\section{Identification of incident RA}

Women who self-reported RA or other CTD were administered a screening questionnaire [37]. For those who screened positive, medical records were obtained to verify the diagnosis and collect symptom/diagnosis dates and serostatus. All records were reviewed by two rheumatologists and all cases had RA by accepted criteria $[38,39]$. We defined seropositive RA as positive rheumatoid factor (RF) or anti-cyclic citrullinated peptide (anti-CCP). We relied on clinical testing so were unable to perform analyses based solely on anti-CCP serostatus since this test was not used clinically when most of the follow-up occurred. The end of follow-up was June 1, 2014 for the NHS and June 1, 2015 for the NHSII.

\section{Covariates}

\section{Sociodemographic, lifestyle, and reproductive factors}

Data on time-varying covariates were obtained through biennial questionnaires. We considered variables that may be associated with fish intake and RA based on prior literature $[4,9,10,40,41]$. Among past/current smokers, we categorized smoking intensity as 1-14 cigarettes/day or $\geq$ 15 cigarettes/day. We calculated smoking pack-years and dichotomized as never/ $\leq 10$ pack-years or $>10$ pack-years [8]. Body mass index (BMI) was categorized as underweight/normal $\left(<25.0 \mathrm{~kg} / \mathrm{m}^{2}\right)$, overweight $(25$ to $<30 \mathrm{~kg} /$ $\left.\mathrm{m}^{2}\right)$, or obese $\left(\geq 30 \mathrm{~kg} / \mathrm{m}^{2}\right)$. Physical activity was measured using a validated survey and converted into weekly metabolic equivalents [42]. We categorized parity and breastfeeding duration into a single variable: nulliparous, parous/breastfeeding for none to < 1 month, parous/ breastfeeding for 1 to $<12$ months, or parous/breastfeeding $\geq 12$ months. Menopausal status and postmenopausal hormone (PMH) use was categorized as: premenopausal, postmenopausal/never PMH use, or postmenopausal/ever $\mathrm{PMH}$ use. We considered household income derived from the US Census tract median income at the level of zip code, categorized into quartiles.

\section{Other dietary factors}

Energy intake was obtained by summing the daily nutritional content of all FFQ items as a continuous variable (kilocalories/day). Alcohol intake was categorized as: none to $<5 \mathrm{~g} /$ day, 5 to $<10 \mathrm{~g} /$ day, or $\geq 10 \mathrm{~g} /$ day. In analyses that included marine omega-3 PUFAs, we also included other PUFA types (alpha-linoleic acid, omega-6 PUFAs), fatty acids (trans, saturated, and monounsaturated), and macronutrients (protein and carbohydrates) as continuous variables (g/day).

\section{Statistical analysis}

We described participants in each cohort according to the baseline distribution of five categories of fish intake using mean and standard deviation (SD) for continuous variables and proportions for categorical variables. We pooled both cohorts into a single analysis to improve statistical efficiency given planned secondary and interaction analyses with low numbers of subgroup outcomes.

Since we previously found differences in metabolic/ dietary RA risk factors related to age $\leq 55$ or $>55$ years old (chosen related to clinical observations of differing RA phenotypes related to age at diagnosis and as an approximation of menopause), we compared clinical characteristics of RA cases by these ages at diagnosis $[9,11$, 13, 14]. Median time from first symptoms to diagnosis were compared by the Wilcoxon-rank sum test. We compared the distribution of 1987 ACR criteria using the chi-square test.

The primary analysis assessed the association of 5 categories of fish intake with all RA risk as well as by serostatus and stratified by age at diagnosis $(\leq 55$ or $>55$ years). Other secondary analyses investigated the association of fish as a binary variable (frequent [ $\geq 1$ serving/ month] or infrequent [none to $<1$ serving/month] intake) with RA risk overall and by serostatus and age stratification. We used Cox proportional hazards models to obtain hazard ratios (HR) and 95\% confidence intervals (CI) for the association of fish intake with RA risk, with the lowest category of fish intake as the reference group. Person-years commenced from the return date of the baseline questionnaire to the end of follow-up, death, or censor, whichever came first. Women were censored for self-reported CTD not confirmed to be RA. We considered the lowest category of fish intake as the reference group. In base models, we adjusted for age, questionnaire period, cohort, and energy. We built multivariable models based on the primary analysis and included covariates that were associated with both fish 
intake and RA risk. The final multivariable model included the base factors as well as median household income, smoking, BMI, and alcohol intake. We calculated $p$ for trend using the median value within each category as a continuous variable in the model.

We investigated the association of quartiles of marine omega-3 PUFAs with the RA outcomes. We considered women in the lowest quartile of intake as the reference group. In these regression models, we also adjusted for other types of PUFAs, fatty acids, and macronutrients to determine the independent of effect of marine omega-3 fatty acids. Since total energy was included, we did not additionally include carbohydrates since all other macronutrients were present.

LLastly, we investigated an interaction between smoking and fish intake, both considered as binary variables (never/ever smoking and frequent/infrequent fish intake). We investigated all RA, as well as stratified analyses based on age at diagnosis $(\leq 55$ or $>55$ years). We created a cross-classified variable as our main exposure, with never smoking/frequent fish intake as the reference group. We obtained $p$ for multiplicative interactions from an interaction term in the model.

We verified the proportional hazards assumption in all analyses by comparing nested models with and without interaction terms of follow-up time and exposure status. A two-sided $p<0.05$ was considered statistically significant.

\section{Results}

Baseline characteristics of both cohorts according to 5 categories of fish intake are shown in Table 1 . In both cohorts $(n=166,013)$, fish intake of none to $<1$ serving/ month occurred infrequently (5.7\% in NHS and $9.3 \%$ in NHSII). Age, race, US region, and reproductive factors were similar regardless of fish intake. Daily energy intake increased as fish intake increased. Those who ate fish frequently were more likely to be ever smokers and had higher income, alcohol intake, and BMI compared to those who infrequently ate fish.

During a total of 3,863,909 person-years of follow-up, there were 1080 incident RA cases. Of these, 672 (62.2\%) were seropositive and 408 (37.8\%) were seronegative. Table 2 shows RA clinical characteristics at presentation according to age at RA diagnosis. Women with RA diagnosed at age $\leq 55$ years tended to have more 1987 ACR criteria $(p=0.016)$ and were more likely to be seropositive $(p=0.020)$ than women diagnosed with RA at age $>55$ years.

The association between 5 categories of cumulative average fish intake and RA risk is shown in Table 3. Compared to infrequent fish intake (none to $<1$ serving/ month), there was no association with more frequent fish intake categories and all RA risk. In the base model adjusted for age, questionnaire period, energy, and cohort, women with fish intake $\geq 4$ servings/week had HR for all RA of $0.92(95 \%$ CI $0.66-1.27$; $p$ for trend $=0.48)$. In the multivariable model additionally adjusted for household income, smoking, BMI, and alcohol intake, the HR for all RA was 0.93 (95\%CI $0.67-1.28 ; p$ for trend $=0.42$ ). We found no association of fish intake with seropositive RA ( $p$ for trend $=0.66$ ), seronegative RA ( $p$ for trend $=0.45$ ), and all RA among women aged $\leq 55$ years ( $p$ for trend $=0.29$ ). While there was no statistically significant trend, the point estimate of the HR tended to be $<1$ compared to none to infrequent fish intake for all categories in all RA, seropositive RA, seronegative RA, and all RA diagnosed $\leq 55$ years old. However, increasing fish intake across 5 categories was associated with increased RA risk among women aged > 55 years ( $p$ for trend $=0.037$ ). In subgroup analyses, there was no association across categories of fish intake with risk of seropositive RA among women $\leq 55$ years ( $p$ for trend $=0.33$ ) or seronegative RA $\leq 55$ years ( $p$ for trend $=0.99$ ).

Table 4 shows the results evaluating a threshold effect for RA risk where infrequent fish intake was considered as none to $<1$ serving/month and frequent fish intake was $\geq 1$ serving/month. Compared to infrequent fish intake, frequent intake was not associated with all RA (multivariable HR 0.85 , 95\%CI 0.64-1.13), seropositive RA (HR 0.86, 95\%CI 0.60-1.22), or seronegative RA (HR 0.85 , 95\%CI $0.53-1.35)$. Among women aged $\leq 55$ years, frequent fish intake was significantly associated with decreased all RA risk in the base model (HR 0.71, 95\%CI $0.50-1.00, p=0.048)$. In the multivariable model, the association of frequent fish intake with reduced RA risk was similar but not statistically significant (HR 0.73, $95 \%$ CI $0.52-1.02, p=0.066$ ). In one subgroup, there was a statistically significant protective effect of frequent fish intake for seronegative RA diagnosed $\leq 55$ years of age (HR 0.55, 95\%CI 0.32-0.94). Frequent fish intake was not associated with RA diagnosed $>55$ years (HR 1.14, 95\%CI 0.69-1.88).

Table 5 shows the results investigating quartiles of marine omega-3 PUFA (EPA, DHA, and DPA) intake with RA risk. There was no association of quartiles of marine omega-3 PUFAs with all RA ( $p$ for trend $=0.28$ ), seropositive RA ( $p$ for trend $=0.19$ ), seronegative RA ( $p$ trend $=0.92$ ), or among those aged $\leq 55$ years ( $p$ for trend $=0.40$ ). There was no association with RA among those aged $>55$ years in the base model ( $p$ for trend $=$ 0.097), but the multivariable model was statistically significant ( $p$ for trend $=0.031$ ). There was no association from lowest to highest quartile of marine omega-3 PUFA intake with risk of seropositive RA among women $\leq 55$ years $(p$ for trend $=0.19$ ) or seronegative RA among 


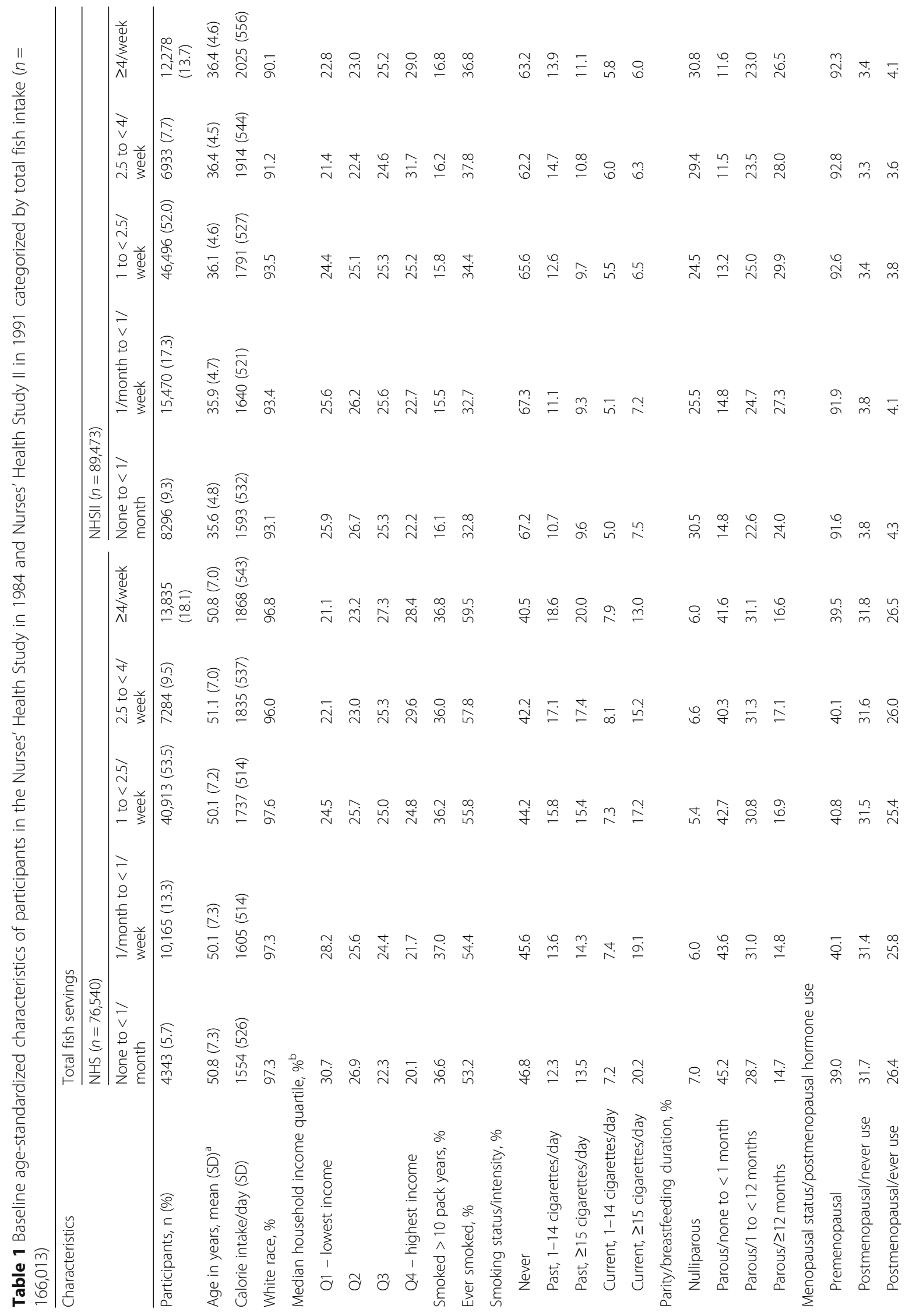




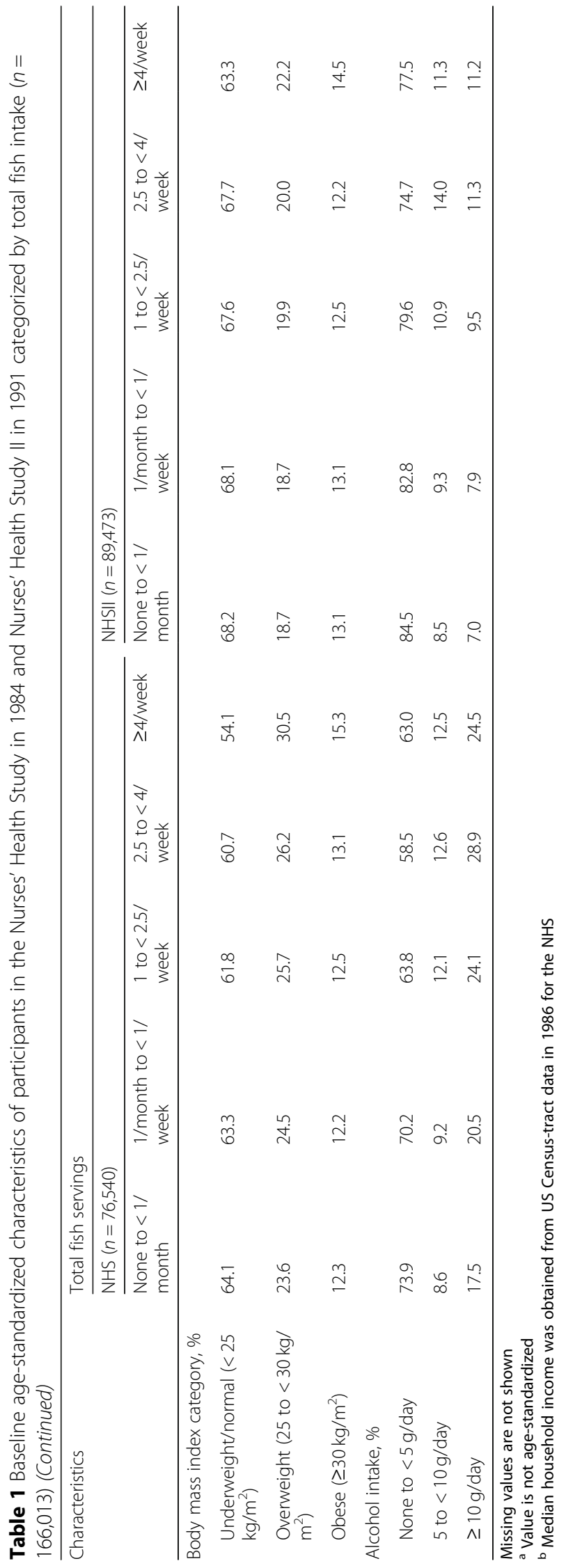


Table 2 Characteristics of 1080 incident rheumatoid arthritis cases at presentation based on diagnosis before or after 55 years of age

\begin{tabular}{llll}
\hline & RA diagnosed $\leq 55$ years $(n=491)$ & RA diagnosed $>55$ years $(n=589)$ & $p$ value \\
\hline Median time from first symptoms to diagnosis, months (IQR) & $7(3,13)$ & $6(2,13)$ & \\
Number of 1987 ACR criteria, \% & & 53.5 & 0.17 \\
4 & 45.2 & 34.8 & 0.016 \\
5 & 43.0 & 11.7 & 59.1 \\
$6-7$ & 11.8 & 28.7 & \\
Seropositive ${ }^{a}, \%$ & 66.0 & 98.0 & 0.020 \\
Radiographic changes, \% & 24.6 & 96.9 & 0.13 \\
Hand arthritis, \% & 98.8 & 93.5 & 0.30 \\
Symmetric arthritis, \% & 96.7 & 73.9 & 0.85 \\
$\geq 3$ joint areas affected, \% & 95.8 & 8.8 & 0.090 \\
$>1$ h of morning stiffness, \% & 75.8 & 0.47 \\
Rheumatoid nodules, \% & 10.0 & 0.52 \\
\hline
\end{tabular}

a Seropositive was defined as positive rheumatoid factor and/or anti-cyclic citrullinated peptide on medical record review

ACR, American College of Rheumatology; IQR, interquartile range; RA, rheumatoid arthritis

women $\leq 55$ years $(p$ for trend $=0.19)$ in these subgroup analyses.

Fig. 1 shows the results comparing RA risk based on smoking status and fish consumption. Ever smokers with infrequent fish intake had increased all RA risk (HR $1.99,95 \%$ CI 1.37-2.89) compared to never smokers with frequent fish intake. However, there was no statistical interaction between fish and smoking for all RA ( $p$ for interaction $=0.086$ ). There was a statistically significant interaction between fish and smoking for RA risk among women aged $\leq 55$ years. In this subgroup, ever smokers with infrequent fish intake had very elevated RA risk (HR 2.59, 95\%CI 1.65-4.06) while ever smokers with frequent fish intake had modestly increased RA risk (HR $1.29,95 \%$ CI 1.07-1.57; vs. never smokers with frequent fish intake; $p$ for interaction $=0.039$ ). There was no smoking-fish interaction among those aged $>55$ years $(p$ for interaction $=0.73$ ).

\section{Discussion}

In this prospective study investigating fish intake and RA risk among 166,013 women with over 3.8 million person-years of follow-up, we found that increasing frequency of fish intake was not associated with overall RA risk or serologic RA phenotypes. Unlike previous studies, we found no evidence for a protective association between marine omega-3 PUFA intake and RA. In one subgroup, we did find a modest inverse association of fish intake above a threshold above 1 serving/month with RA risk, but only for earlier onset seronegative RA (age $\leq 55$ years). While our results suggest that fish intake may attenuate the increased RA risk among ever smokers in this younger age group, fish intake may actually increase RA risk among older individuals $>55$ years of age. Overall, these results do not support a strong effect of fish or omega-3 fatty acid intake on RA risk.

Our study adds to the literature of a relationship between fish intake and RA risk [30]. Several case-control studies suggested that fish intake, particularly dark meat/oily fish, was associated with decreased RA risk [23-25, 28]. These studies may have been limited due to recall bias and were conducted in coastal geographic areas with high fish intake (US Pacific Northwest, Greece, and Sweden) [23-25, 28]. Only one of these case-control studies adjusted for smoking [28]. Two studies investigated fish and seropositive RA risk but were underpowered for definitive conclusions [24, 28].

Fish intake and RA risk was investigated previously in cohort studies [26, 27, 29]. In a Danish study, fish intake on a single FFQ was not associated with RA, but there were few RA outcomes, so it may have been underpowered [26]. The Swedish Mammography cohort that analyzed two FFQ assessments may have suggested a modest, albeit statistically non-significant, decreased RA risk for fish intake $\geq 1$ serving/week (RR $0.71,95 \% \mathrm{CI}$ $0.48-1.04)$, but analyses were not stratified by age [29]. They found that omega-3 PUFA intake above the threshold of the first quartile $(>0.21 \mathrm{~g} /$ day $)$ was protective for RA risk (RR 0.65, 95\%CI 0.48-0.90) [29]. Our omega-3 PUFA intake analyses did not detect a protective effect. While that study adjusted for smoking, the authors did not stratify by age at diagnosis, and fish-smoking interactions were not studied [29]. Our group previously investigated fish intake, among other dietary factors, and RA risk in the NHS and found no association [27]. This present report nearly doubles the number of incident RA cases by extending follow-up by 12 years and including the NHSII, allowing for increased power as well as 
Table 3 Hazard ratios for rheumatoid arthritis phenotypes according to categories of cumulative average total fish intake in the Nurses' Health Study and Nurses' Health Study II $(n=166,013)$

\begin{tabular}{|c|c|c|c|c|c|c|}
\hline & \multicolumn{4}{|l|}{ Total fish servings } & \multirow{3}{*}{$\begin{array}{l}\geq 4 / \text { week } \\
\text { HR }(95 \% \mathrm{Cl})\end{array}$} & \multirow{3}{*}{$\begin{array}{l}p \text { for } \\
\text { trend }\end{array}$} \\
\hline & None to $<1 /$ month & $1 /$ month to $<1 /$ week & 1 to $<2.5 /$ week & 2.5 to $<4 /$ week & & \\
\hline & HR $(95 \% \mathrm{Cl})$ & $\mathrm{HR}(95 \% \mathrm{Cl})$ & $\mathrm{HR}(95 \% \mathrm{Cl})$ & $\mathrm{HR}(95 \% \mathrm{Cl})$ & & \\
\hline \multicolumn{7}{|l|}{ All RA } \\
\hline Cases/person-years & $53 / 185,861$ & $175 / 705,447$ & $513 / 1,888,251$ & $200 / 649,928$ & $139 / 434,424$ & \\
\hline Age-adjusted model ${ }^{a}$ & 1.00 (Ref) & $0.82(0.60-1.11)$ & $0.83(0.62-1.11)$ & $0.87(0.64-1.19)$ & $0.92(0.66-1.27)$ & 0.48 \\
\hline Multivariable model $^{b}$ & 1.00 (Ref) & $0.82(0.60-1.12)$ & $0.84(0.63-1.12)$ & $0.89(0.65-1.22)$ & $0.93(0.67-1.28)$ & 0.42 \\
\hline \multicolumn{7}{|l|}{ Seropositive RA } \\
\hline Cases/person-years & $34 / 185,640$ & $116 / 704,320$ & $308 / 1,884,304$ & $133 / 648,527$ & $81 / 433,284$ & \\
\hline Age-adjusted model $^{a}$ & 1.00 (Ref) & $0.86(0.59-1.27)$ & $0.80(0.56-1.15)$ & $0.95(0.64-1.39)$ & $0.87(0.57-1.31)$ & 0.72 \\
\hline Multivariable model $^{b}$ & 1.00 (Ref) & $0.86(0.59-1.27)$ & $0.82(0.57-1.17)$ & $0.97(0.66-1.43)$ & $0.88(0.58-1.33)$ & 0.66 \\
\hline \multicolumn{7}{|l|}{ Seronegative RA } \\
\hline Cases/person-years & $19 / 185,340$ & $59 / 703,876$ & $205 / 1,883,542$ & $67 / 648,136$ & $58 / 432,966$ & \\
\hline Age-adjusted model ${ }^{a}$ & 1.00 (Ref) & $0.74(0.44-1.25)$ & $0.88(0.54-1.41)$ & $0.76(0.45-1.27)$ & $0.99(0.59-1.69)$ & 0.48 \\
\hline Multivariable model $^{b}$ & 1.00 (Ref) & $0.74(0.44-1.25)$ & $0.88(0.55-1.42)$ & $0.77(0.46-1.29)$ & $1.01(0.59-1.71)$ & 0.45 \\
\hline \multicolumn{7}{|l|}{ All RA among $\leq 55$ years } \\
\hline Cases/person-years & $37 / 134,613$ & $113 / 458,908$ & $213 / 1,072,596$ & $74 / 301,548$ & $54 / 224,372$ & \\
\hline Age-adjusted model ${ }^{\mathrm{a}}$ & 1.00 (Ref) & $0.85(0.59-1.24)$ & $0.64(0.45-0.91)$ & $0.72(0.48-1.08)$ & $0.71(0.46-1.10)$ & 0.25 \\
\hline Multivariable model $^{b}$ & 1.00 (Ref) & $0.86(0.59-1.25)$ & $0.66(0.46-0.94)$ & $0.75(0.50-1.12)$ & $0.72(0.47-1.11)$ & 0.29 \\
\hline \multicolumn{7}{|l|}{ All RA among $>55$ years } \\
\hline Cases/person-years & $16 / 52,659$ & $62 / 252,365$ & $300 / 828,551$ & $126 / 352,538$ & $85 / 211,857$ & \\
\hline Age-adjusted model ${ }^{a}$ & 1.00 (Ref) & $0.82(0.47-1.42)$ & $1.19(0.72-1.98)$ & $1.19(0.70-2.01)$ & $1.30(0.75-2.23)$ & 0.043 \\
\hline Multivariable model $^{\mathrm{b}}$ & 1.00 (Ref) & $0.82(0.47-1.42)$ & $1.21(0.73-2.00)$ & $1.21(0.71-2.05)$ & $1.32(0.76-2.27)$ & 0.037 \\
\hline
\end{tabular}

There were 1080 cases in 3,863,909 total person-years for all RA analyses. There were 672 cases in 3,856,074 total person-years for seropositive RA analyses There were 408 cases in 3,853,860 total person-years for seronegative RA analyses. There were 491 cases in 2,192,037 total person-years for all RA among $\leq 55$ years analyses. There were 589 cases in 1,697,970 total person-years for all RA among $>55$ years analyses

The exposure period was 1984 to 2012 for cases occurring until 2014 in the NHS; the exposure period was 1991 to 2013 for cases occurring until 2015 in the NHSII

a Adjusted for age, questionnaire period, cohort, and total energy intake (continuous)

${ }^{\mathrm{b}}$ Multivariable models were adjusted for age, questionnaire period, cohort, total energy intake (continuous), median household income (quartiles), cigarette smoking (never, past 1-14/day, past $\geq 15 /$ day, current 1-14/day, current $\geq 15 /$ day), body mass index category (underweight/normal, overweight, obese), and alcohol intake (never to $<5,5$ to $<10, \geq 10 \mathrm{~g} /$ day)

$\mathrm{Cl}$ confidence interval, $H R$ hazard ration, $R A$ rheumatoid arthritis

subgroup analyses of RA phenotypes and smoking-fish interaction analyses. Despite adequate sample size and number of outcomes, our study did not find a protective effect on seropositive RA.

Several investigations in the Studies of the Etiology of RA (SERA) suggest that omega-3 PUFAs may be particularly important in the preclinical transitions preceding clinical RA presentation. Among those with the shared epitope or RA-related autoantibodies, omega-3 supplement use and erythrocyte-bound PUFAs were inversely associated with anti-CCP, RF positivity, and inflammatory arthritis [16-18]. Another SERA study reported that early age and smoking are both important factors for inflammatory arthritis [43]. Our results suggest that fish intake may be relatively more beneficial among younger/middle-aged women who were ever smokers. Since smokers may have increased systemic inflammation, long-term fish intake may exert effects by lowering inflammation once present due to smoking or other factors. A European nested case-control study showed that erythrocyte-bound omega- 6 PUFAs, but not omega-3 PUFAs, were inversely associated with RA risk, so the effect of PUFAs on RA is still unclear [44]. Given the number of comparisons pursued in our study, the finding of the smoking-fish interaction should be considered as exploratory. While erythrocyte-bound assays and intake on FFQ have both been validated as measures of omega-3 PUFAs, they are only modestly correlated with each other, and it is unclear how much fish intake is needed for a meaningful increase in erythrocyte measures of omega-3 PUFAs [32, 45]. Therefore, the differences in our findings and the studies in SERA may be related to these different measures of omega-3 PUFAs in addition to studying different outcomes (surrogates of 
Table 4 Hazard ratios for rheumatoid arthritis phenotypes according to dichotomized cumulative average total fish intake in the Nurses' Health Study and Nurses' Health Study II $(n=166,013)$

\begin{tabular}{|c|c|c|c|}
\hline & \multicolumn{3}{|l|}{ Total fish servings } \\
\hline & None to $<1 /$ month (low) & $\geq 1 /$ month (high) & $p$ value \\
\hline & HR $(95 \% \mathrm{Cl})$ & $\mathrm{HR}(95 \% \mathrm{Cl})$ & \\
\hline \multicolumn{4}{|l|}{ All RA } \\
\hline Cases/person-years & $53 / 185,861$ & $1027 / 3,678,049$ & \\
\hline Age-adjusted model $^{a}$ & 1.00 (Ref) & $0.84(0.64-1.11)$ & 0.23 \\
\hline Multivariable model $^{\mathrm{b}}$ & 1.00 (Ref) & $0.85(0.64-1.13)$ & 0.27 \\
\hline \multicolumn{4}{|l|}{ Seropositive RA } \\
\hline Cases/person-years & $34 / 185,640$ & $638 / 3,670,434$ & \\
\hline Age-adjusted model $\left.\right|^{a}$ & 1.00 (Ref) & $0.84(0.59-1.20)$ & 0.34 \\
\hline Multivariable model $^{b}$ & 1.00 (Ref) & $0.86(0.60-1.22)$ & 0.39 \\
\hline \multicolumn{4}{|l|}{ Seronegative RA } \\
\hline Cases/person-years & $19 / 185,340$ & $389 / 3,668,519$ & \\
\hline Age-adjusted model $^{a}$ & 1.00 (Ref) & $0.84(0.53-1.34)$ & 0.47 \\
\hline Multivariable model $^{\mathrm{b}}$ & 1.00 (Ref) & $0.85(0.53-1.35)$ & 0.48 \\
\hline \multicolumn{4}{|l|}{ All RA among $\leq 55$ years } \\
\hline Cases/person-years & $37 / 134,613$ & $454 / 2,057,424$ & \\
\hline Age-adjusted model $^{a}$ & 1.00 (Ref) & $0.71(0.50-1.00)$ & 0.048 \\
\hline Multivariable model $^{b}$ & 1.00 (Ref) & $0.73(0.52-1.02)$ & 0.066 \\
\hline \multicolumn{4}{|c|}{ Seropositive RA among $\leq 55$ years } \\
\hline Cases/person-years & $22 / 134,452$ & $302 / 2,053,251$ & \\
\hline Age-adjusted model $^{a}$ & 1.00 (Ref) & $0.83(0.53-1.29)$ & 0.40 \\
\hline Multivariable model $^{\mathrm{b}}$ & 1.00 (Ref) & $0.85(0.55-1.32)$ & 0.47 \\
\hline \multicolumn{4}{|c|}{ Seronegative RA among $\leq 55$ years } \\
\hline Cases/person-years & $15 / 134,186$ & $152 / 2,051,358$ & \\
\hline Age-adjusted model $^{a}$ & 1.00 (Ref) & $0.54(0.31-0.92)$ & 0.024 \\
\hline Multivariable model $^{b}$ & 1.00 (Ref) & $0.55(0.32-0.94)$ & 0.029 \\
\hline \multicolumn{4}{|l|}{ All RA among $>55$ years } \\
\hline Cases/person-years & $16 / 52,659$ & $573 / 1,645,311$ & \\
\hline Age-adjusted model $^{a}$ & 1.00 (Ref) & $1.13(0.69-1.87)$ & 0.62 \\
\hline Multivariable model $^{\mathrm{b}}$ & 1.00 (Ref) & $1.14(0.69-1.88)$ & 0.60 \\
\hline
\end{tabular}

RA such as presence of RA-related autoantibodies in SERA vs. onset of RA in our study).

Strengths of our study include a large sample size, long follow-up, and many RA outcomes with detailed dietary/ covariate data. We were able to investigate fish intake and risk of RA phenotypes based on serostatus and age at diagnosis. We used a prospective cohort design, so time-varying fish intake measures were collected prior to RA onset and less likely to be affected by recall bias. Women had multiple repeated measures of diet during follow-up and we analyzed the cumulative average fish intake to reflect long-term dietary intake. A recent study showed that unaffected relatives of RA were patients unaware that fish intake may affect RA risk and were motivated to change behaviors after a personalized RA risk educational intervention $[46,47]$. However, this dietary recommendation may have at best only a modest effect on RA risk.

Our study has limitations to consider. The cohorts included mostly white and educated women who were 
Table 5 Hazard ratios for rheumatoid arthritis phenotypes according to quartiles of marine omega-3 polyunsaturated fatty acid ${ }^{a}$ intake in the Nurses' Health Study and Nurses' Health Study II $(n=166,013)$

\begin{tabular}{|c|c|c|c|c|c|}
\hline & \multicolumn{5}{|c|}{ Marine omega-3 polyunsaturated fatty acid intake ${ }^{a}$} \\
\hline & Quartile 1 & Quartile 2 & Quartile 3 & Quartile 4 & \multirow{2}{*}{$\begin{array}{l}p \text { for } \\
\text { trend }\end{array}$} \\
\hline & HR $(95 \% \mathrm{Cl})$ & $\mathrm{HR}(95 \% \mathrm{Cl})$ & $\mathrm{HR}(95 \% \mathrm{Cl})$ & $\mathrm{HR}(95 \% \mathrm{Cl})$ & \\
\hline \multicolumn{6}{|l|}{ All RA } \\
\hline Cases/person-years & $251 / 945,683$ & $269 / 969,619$ & $279 / 980,365$ & $281 / 968,243$ & \\
\hline Age-adjusted model $^{b}$ & 1.00 (Ref) & $1.03(0.87-1.22)$ & $1.05(0.88-1.24)$ & $1.04(0.88-1.24)$ & 0.65 \\
\hline Multivariable model ${ }^{c}$ & 1.00 (Ref) & $1.05(0.88-1.25)$ & $1.09(0.91-1.31)$ & $1.12(0.91-1.37)$ & 0.28 \\
\hline \multicolumn{6}{|l|}{ Seropositive RA } \\
\hline Cases/person-years & $167 / 943,993$ & $153 / 967,552$ & $177 / 978,198$ & $175 / 966,331$ & \\
\hline Age-adjusted model ${ }^{\mathrm{b}}$ & 1.00 (Ref) & $0.88(0.70-1.09)$ & $1.00(0.81-1.23)$ & $0.97(0.79-1.21)$ & 0.82 \\
\hline Multivariable model $^{c}$ & 1.00 (Ref) & $0.92(0.73-1.15)$ & $1.08(0.86-1.36)$ & $1.12(0.87-1.43)$ & 0.19 \\
\hline \multicolumn{6}{|l|}{ Seronegative RA } \\
\hline Cases/person-years & $84 / 943,360$ & $116 / 967,367$ & $102 / 977,670$ & $106 / 965,464$ & \\
\hline Age-adjusted model ${ }^{\mathrm{b}}$ & 1.00 (Ref) & $1.34(1.01-1.77)$ & $1.14(0.86-1.53)$ & $1.18(0.89-1.58)$ & 0.64 \\
\hline Multivariable model $^{c}$ & 1.00 (Ref) & $1.31(0.98-1.75)$ & $1.12(0.82-1.51)$ & $1.14(0.81-1.59)$ & 0.92 \\
\hline \multicolumn{6}{|l|}{ All RA among $\leq 55$ years } \\
\hline Cases/person-years & $125 / 565,147$ & $139 / 564,890$ & $120 / 548,635$ & $107 / 513,366$ & \\
\hline Age-adjusted model ${ }^{b}$ & 1.00 (Ref) & $1.10(0.87-1.41)$ & $0.96(0.75-1.24)$ & $0.90(0.69-1.17)$ & 0.23 \\
\hline Multivariable model $^{c}$ & 1.00 (Ref) & $1.10(0.86-1.41)$ & $0.98(0.75-1.27)$ & $0.93(0.69-1.25)$ & 0.40 \\
\hline \multicolumn{6}{|l|}{ All RA among $>55$ years } \\
\hline Cases/person-years & $126 / 386,863$ & $130 / 411,627$ & $159 / 438,231$ & $174 / 461,250$ & \\
\hline Age-adjusted model ${ }^{\mathrm{b}}$ & 1.00 (Ref) & $0.96(0.75-1.23)$ & $1.12(0.89-1.42)$ & $1.16(0.92-1.47)$ & 0.097 \\
\hline Multivariable model ${ }^{c}$ & 1.00 (Ref) & $1.00(0.77-1.28)$ & $1.20(0.93-1.54)$ & $1.29(0.98-1.69)$ & 0.031 \\
\hline
\end{tabular}

a Dietary and supplementary intake of eicosapentaenoic acid (EPA), docosahexaenoic acid (DHA), and docosapentaenoic acid (DPA) were considered as marine omega-3 polyunsaturated fatty acids

${ }^{\mathrm{b}}$ Adjusted for age, questionnaire period, cohort, and total energy intake (continuous)

'Multivariable models were adjusted for age, questionnaire period, cohort, total energy intake (continuous), median household income (quartiles), cigarette smoking (never, past 1-14/day, past $\geq 14 /$ day, current 1-14/day, current $\geq 14 /$ day), body mass index category (underweight/normal, overweight, obese), alcohol intake (never to $<5,5$ to $<10, \geq 10 \mathrm{~g} /$ day), alpha-linolenic acid (g/d), trans fatty acids $(\mathrm{g} / \mathrm{d})$, saturated fatty acids $(\mathrm{g} / \mathrm{d})$, monounsaturated fatty acids ( $\mathrm{g} / \mathrm{d}$ ), omega- 6 polyunsaturated fatty acids $(\mathrm{g} / \mathrm{d})$, and protein $(\mathrm{g} / \mathrm{d})$

$\mathrm{Cl}$ confidence interval, $H R$ hazard ratio, $R A$ rheumatoid arthritis

healthy and working at baseline, so may not be generalizable. However, about two-thirds of patients with RA are women but it is unclear whether fish intake would have a similar effect on RA risk for men. While the FFQ has been widely used as a survey instrument to collect dietary data, it may not be completely accurate. Moreover, given the period of observation, fish consumption was low and often in the form of tuna, rather than other types of fresh fish, which likely has more powerful effects on increasing omega-3 PUFA levels. We were able to adjust for important covariates, such as smoking and BMI, but residual confounding is still possible. While we found a modest inverse association between fish intake and RA risk among women $\leq 55$ years of age, we found no association of omega-3 PUFA intake with RA, even among this subgroup. It is possible that these could be chance findings related to multiple comparisons, though we pre-specified hypotheses based on literature [11, 43]. Our group has found differences related to elevated BMI and other dietary factors for RA occurring at less than 55 years which may be related to biologic differences based on menopause $[9,11,13,14]$. Most of the participants in the SERA studies investigating omega-3 PUFAs and RA outcomes were younger than 55 years, but these studies were not specifically restricted to premenopausal women [16-18]. Less than $10 \%$ of women in both cohorts were categorized as having infrequent fish intake, so most women that were analyzed met this threshold and there were only a few cases that occurred in the infrequent fish intake category. However, in the main analysis investigating 5 categories of fish intake, there was no clear effect of higher categories of fish intake for reducing RA risk. We found no protective association of fish intake with seropositive 


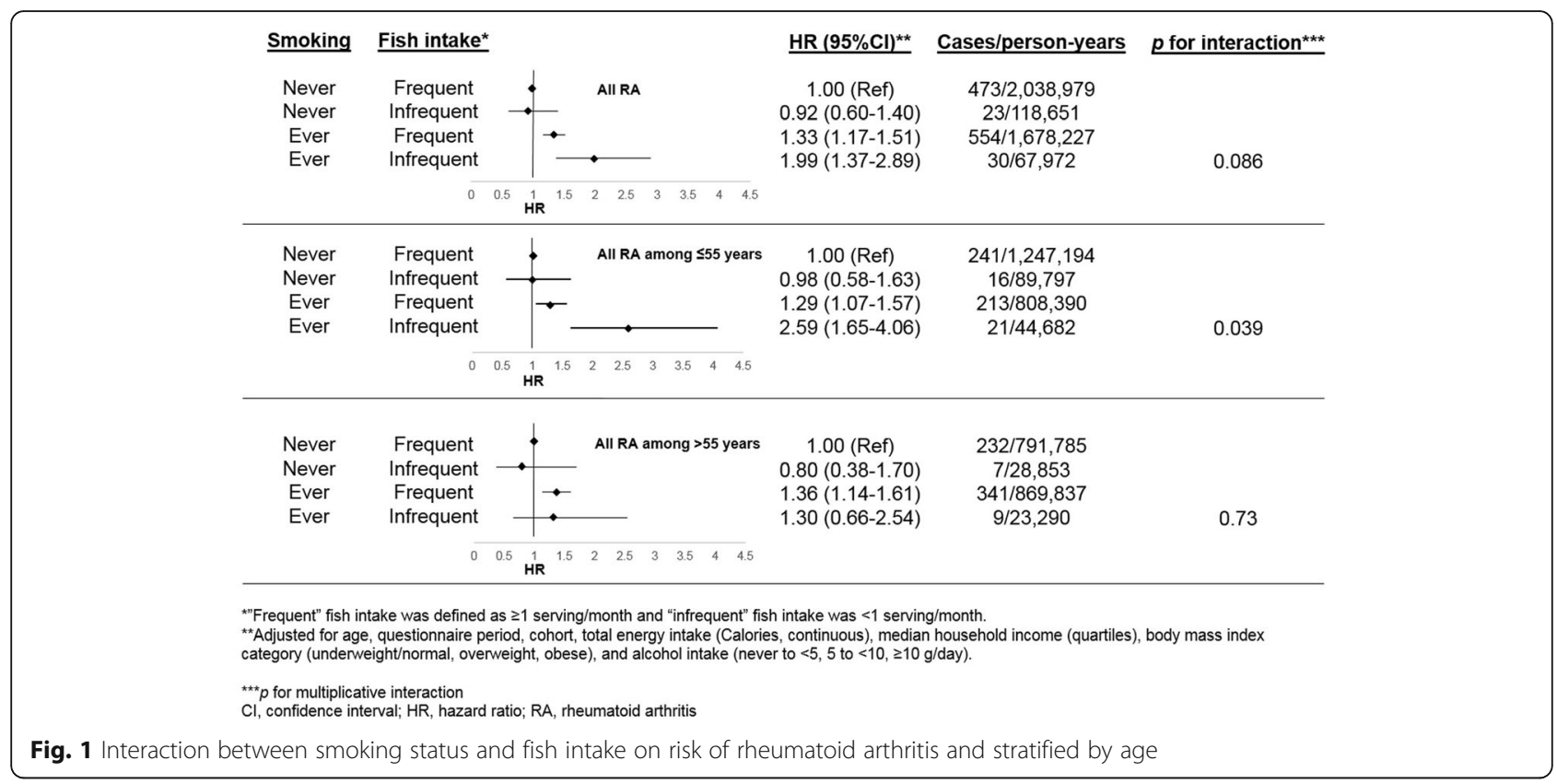

RA and actually found an increased risk for RA diagnosed at $>55$ years, both contrary to our hypothesis and previous studies $[16,24]$.

\section{Conclusions}

In conclusion, our study did not find an association of fish intake or marine omega-3 PUFA intake with overall, seropositive, or seronegative RA risk. We found a suggestion that increasing fish intake may actually increase RA risk for women diagnosed at age $>55$ years. We identified a smoking-fish interaction, such that ever smokers with frequent fish intake had only a modestly increased earlier-onset RA risk compared to the very elevated RA risk of smokers with infrequent fish intake. Our study does not provide evidence to recommend fish or omega-3 fatty acid intake to those at risk for RA.

\section{Abbreviations \\ Anti-CCP: Anti-cyclic citrullinated peptide; BMI: Body mass index; $\mathrm{Cl}$ : Confidence interval; CSQ: Connective tissue disease screening questionnaire; CTD: Connective tissue disease; DHA: Docosahexaenoic acid; DPA: Docosapentaenoic acid; EPA: Eicosapentaenoic acid; FFQ: Food frequency questionnaire; HR: Hazard ratio; NHS: Nurses' health study; NHSII: Nurses' health study II; PMH: Postmenopausal hormone; PUFA: Polyunsaturated fatty acid; RA: Rheumatoid arthritis; RF: Rheumatoid factor; SD: Standard deviation}

\section{Acknowledgements}

The authors thank the participants of the NHS and NHSII for their dedicated participation in this longitudinal study as well as the staff members at the Channing division of network medicine (Department of Medicine, Brigham and Women's hospital and Harvard Medical School) for helpful guidance.

\section{Funding}

This work was supported by the National Institutes of Health (grant numbers K24 AR052403, P60 AR047782, L30 AR066953, L30 AR070514, R01 AR049880, UM1 CA186107, UM1 CA176726, K23 AR069688, K24 AR066109, T32 AR007530, P30 AR070253, and P30 AR072577). Dr. Barbhaiya is supported by the Rheumatology Research Foundation Scientist Development Award. The funders had no role in study design, data collection, analysis, decision to publish, or preparation of the manuscript. The content is solely the responsibility of the authors and does not necessarily represent the official views of Harvard University, its affiliated academic health care centers, or the National Institutes of Health.

\section{Availability of data and materials}

The datasets generated and analyzed during the current study are available through the Channing School of Medicine at Brigham and Women's Hospital in Boston, MA through queries directed at http://www.nurseshealthstudy.org/.

\section{Authors' contributions}

All authors (JS, ÉO, MB, ST, SM, BL, WW, KC, EK) were involved in drafting the article or revising it critically for important intellectual contact, and all authors approved the final version to be published. JS had full access to all of the data in the study and takes responsibility for the integrity of the data and the accuracy of the data analysis. Study conception and design: JS, ÉO, EK. Acquisition of data: JS, MB, ST, WW, KC, EW. Analysis and interpretation of data: JS, ÉO, MB, ST, SM, BL, WW, KC, EK.

Ethics approval and consent to participate

All aspects of the study were approved by the Partners HealthCare Institutional Review Board. All participants signed informed consent.

Consent for publication

Not applicable.

Competing interests

The authors' declare that they have no competing interests.

\section{Publisher's Note}

Springer Nature remains neutral with regard to jurisdictional claims in published maps and institutional affiliations.

\section{Author details}

'Department of Medicine, Division of Rheumatology, Immunology and Allergy, Brigham and Women's Hospital, 60 Fenwood Road, \#6016U, Boston, MA 02115, USA. 'Harvard Medical School, 25 Shattuck St, Boston, MA 02115, USA. ${ }^{3}$ Department of Nutrition, Harvard T.H. Chan School of Public Health, 677 Huntington Ave, Boston, MA 02115, USA. ${ }^{S}$ School of Public Health, University College Cork, University College, College Road, Cork, Ireland. ${ }^{5}$ Hospital for Special Surgery, 535 East 70th Street, New York, NY 10021, USA. 
${ }^{6}$ Department of Medicine, Channing Division of Network Medicine, Brigham and Women's Hospital, 181 Longwood Avenue, Boston, MA 02115, USA.

\section{Received: 3 July 2018 Accepted: 17 December 2018} Published online: 05 January 2019

\section{References}

1. Deane KD, Demoruelle MK, Kelmenson LB, Kuhn KA, Norris JM, Holers VM. Genetic and environmental risk factors for rheumatoid arthritis. Best Pract Res Clin Rheumatol. 2017;31(1):3-18.

2. Lahiri M, Morgan C, Symmons DP, Bruce IN. Modifiable risk factors for RA: prevention, better than cure? Rheumatology (Oxford). 2012;51(3):499-512.

3. Dekkers J, Toes RE, Huizinga TW, van der Woude D. The role of anticitrullinated protein antibodies in the early stages of rheumatoid arthritis. Curr Opin Rheumatol. 2016:28(3):275-81.

4. Costenbader KH, Feskanich D, Mandl LA, Karlson EW. Smoking intensity, duration, and cessation, and the risk of rheumatoid arthritis in women. Am J Med. 2006;119(6):503 e1-9.

5. Di Giuseppe D, Discacciati A, Orsini N, Wolk A. Cigarette smoking and risk of rheumatoid arthritis: a dose-response meta-analysis. Arthritis Res Ther. 2014; 16(2):R61.

6. Kallberg H, Ding B, Padyukov L, Bengtsson C, Ronnelid J, Klareskog L, et al. Smoking is a major preventable risk factor for rheumatoid arthritis: estimations of risks after various exposures to cigarette smoke. Ann Rheum Dis. 2011;70(3):508-11.

7. Sparks JA, Karlson EW. The roles of cigarette smoking and the lung in the transitions between phases of preclinical rheumatoid arthritis. Curr Rheumatol Rep. 2016;18(3):15.

8. Kim K, Jiang X, Cui J, Lu B, Costenbader KH, Sparks JA, et al. Interactions between amino acid-defined major histocompatibility complex class II variants and smoking in seropositive rheumatoid arthritis. Arthritis Rheumatol. 2015;67(10):2611-23.

9. Lu B, Hiraki LT, Sparks JA, Malspeis S, Chen CY, Awosogba JA, et al. Being overweight or obese and risk of developing rheumatoid arthritis among women: a prospective cohort study. Ann Rheum Dis. 2014;73(11):1914-22.

10. Lu B, Solomon DH, Costenbader KH, Karlson EW. Alcohol consumption and risk of incident rheumatoid arthritis in women: a prospective study. Arthritis Rheumatol. 2014;66(8):1998-2005.

11. Hu Y, Sparks JA, Malspeis S, Costenbader KH, Hu FB, Karlson EW, et al. Longterm dietary quality and risk of developing rheumatoid arthritis in women. Ann Rheum Dis. 2017;76(8):1357-64.

12. Qin B, Yang M, Fu H, Ma N, Wei T, Tang Q, et al. Body mass index and the risk of rheumatoid arthritis: a systematic review and dose-response metaanalysis. Arthritis Res Ther. 2015;17:86.

13. Hu Y, Costenbader KH, Gao X, Al-Daabil M, Sparks JA, Solomon DH, et al. Sugar-sweetened soda consumption and risk of developing rheumatoid arthritis in women. Am J Clin Nutr. 2014;100(3):959-67.

14. Sparks JA, Barbhaiya M, Tedeschi SK, Leatherwood CL, Tabung FK, Speyer $\mathrm{CB}$, et al. Inflammatory dietary pattern and risk of developing rheumatoid arthritis in women. Clin Rheumatol. 2018. https://doi.org/10.1007/s10067018-4261-5. [Epub ahead of print].

15. Siriwardhana N, Kalupahana NS, Moustaid-Moussa N. Health benefits of $n-3$ polyunsaturated fatty acids: eicosapentaenoic acid and docosahexaenoic acid. Adv Food Nutr Res. 2012:65:211-22.

16. Gan RW, Young KA, Zerbe GO, Demoruelle MK, Weisman MH, Buckner JH, et al. Lower omega-3 fatty acids are associated with the presence of anticyclic citrullinated peptide autoantibodies in a population at risk for future rheumatoid arthritis: a nested case-control study. Rheumatology (Oxford). 2016;55(2):367-76

17. Gan RW, Demoruelle MK, Deane KD, Weisman MH, Buckner JH, Gregersen PK, et al. Omega-3 fatty acids are associated with a lower prevalence of autoantibodies in shared epitope-positive subjects at risk for rheumatoid arthritis. Ann Rheum Dis. 2017;76(1):147-52.

18. Gan RW, Bemis EA, Demoruelle MK, Striebich CC, Brake S, Feser ML, et al. The association between omega-3 fatty acid biomarkers and inflammatory arthritis in an anti-citrullinated protein antibody positive population. Rheumatology (Oxford). 2017;56(12):2229-36.

19. Tedeschi SK, Bathon JM, Giles JT, Lin TC, Yoshida K, Solomon DH. The relationship between fish consumption and disease activity in rheumatoid arthritis. Arthritis Care Res (Hoboken). 2017;70(3):327-32.
20. Proudman SM, James MJ, Spargo LD, Metcalf RG, Sullivan TR, Rischmueller $M$, et al. Fish oil in recent onset rheumatoid arthritis: a randomised, doubleblind controlled trial within algorithm-based drug use. Ann Rheum Dis. 2015;74(1):89-95.

21. Lee YH, Bae SC, Song GG. Omega-3 polyunsaturated fatty acids and the treatment of rheumatoid arthritis: a meta-analysis. Arch Med Res. 2012;43(5): $356-62$.

22. Lourdudoss C, Di Giuseppe D, Wolk A, Westerlind H, Klareskog L, Alfredsson $L$, et al. Dietary intake of polyunsaturated fatty acids and pain in spite of inflammatory control among methotrexate-treated early rheumatoid arthritis patients. Arthritis Care Res (Hoboken). 2018;70(2):205-12.

23. Linos A, Kaklamanis E, Kontomerkos A, Koumantaki Y, Gazi S, Vaiopoulos G, et al. The effect of olive oil and fish consumption on rheumatoid arthritis--a case control study. Scand J Rheumatol. 1991;20(6):419-26.

24. Shapiro JA, Koepsell TD, Voigt LF, Dugowson CE, Kestin M, Nelson JL. Diet and rheumatoid arthritis in women: a possible protective effect of fish consumption. Epidemiology. 1996;7(3):256-63.

25. Linos A, Kaklamani VG, Kaklamani E, Koumantaki Y, Giziaki E, Papazoglou S, et al. Dietary factors in relation to rheumatoid arthritis: a role for olive oil and cooked vegetables? Am J Clin Nutr. 1999;70(6):1077-82.

26. Pedersen M, Stripp C, Klarlund M, Olsen SF, Tjonneland AM, Frisch M. Diet and risk of rheumatoid arthritis in a prospective cohort. J Rheumatol. 2005; 32(7):1249-52.

27. Benito-Garcia E, Feskanich D, Hu FB, Mandl LA, Karlson EW. Protein, iron, and meat consumption and risk for rheumatoid arthritis: a prospective cohort study. Arthritis Res Ther. 2007;9(1):R16.

28. Rosell M, Wesley AM, Rydin K, Klareskog L, Alfredsson L, Group Es. Dietary fish and fish oil and the risk of rheumatoid arthritis. Epidemiology. 2009; 20(6):896-901.

29. Di Giuseppe D, Wallin A, Bottai M, Askling J, Wolk A. Long-term intake of dietary long-chain n-3 polyunsaturated fatty acids and risk of rheumatoid arthritis: a prospective cohort study of women. Ann Rheum Dis. 2014;73(11):1949-53.

30. Di Giuseppe D, Crippa A, Orsini N, Wolk A. Fish consumption and risk of rheumatoid arthritis: a dose-response meta-analysis. Arthritis Res Ther. 2014; 16(5):446.

31. Hu Y, Costenbader KH, Gao X, Hu FB, Karlson EW, Lu B. Mediterranean diet and incidence of rheumatoid arthritis in women. Arthritis Care Res (Hoboken). 2015;67(5):597-606.

32. Yuan C, Spiegelman D, Rimm EB, Rosner BA, Stampfer MJ, Barnett JB, et al. Validity of a dietary questionnaire assessed by comparison with multiple weighed dietary records or 24-hour recalls. Am J Epidemiol. 2017;185(7): $570-84$.

33. Feskanich D, Rimm EB, Giovannucci EL, Colditz GA, Stampfer MJ, Litin LB, et al. Reproducibility and validity of food intake measurements from a semiquantitative food frequency questionnaire. J Am Diet Assoc. 1993;93(7):790-6.

34. Hu FB, Bronner L, Willett WC, Stampfer MJ, Rexrode KM, Albert CM, et al. Fish and omega-3 fatty acid intake and risk of coronary heart disease in women. JAMA. 2002;287(14):1815-21.

35. Varraso R, Barr RG, Willett WC, Speizer FE, Camargo CA Jr. Fish intake and risk of chronic obstructive pulmonary disease in 2 large US cohorts. Am J Clin Nutr. 2015;101(2):354-61.

36. Fitzgerald KC, O'Reilly EJ, Falcone GJ, McCullough ML, Park Y, Kolonel LN, et al. Dietary omega-3 polyunsaturated fatty acid intake and risk for amyotrophic lateral sclerosis. JAMA Neurol. 2014;71(9):1102-10.

37. Karlson EW, Sanchez-Guerrero J, Wright EA, Lew RA, Daltroy LH, Katz JN, et al. A connective tissue disease screening questionnaire for population studies. Ann Epidemiol. 1995;5(4):297-302.

38. Arnett FC, Edworthy SM, Bloch DA, McShane DJ, Fries JF, Cooper NS, et al. The American rheumatism association 1987 revised criteria for the classification of rheumatoid arthritis. Arthritis Rheum. 1988;31(3):315-24.

39. Aletaha D, Neogi T, Silman AJ, Funovits J, Felson DT, Bingham CO 3rd, et al. Rheumatoid arthritis classification criteria: an American College of Rheumatology/European League Against Rheumatism collaborative initiative. Arthritis Rheum. 2010;62(9):2569-81.

40. Karlson EW, Mandl LA, Hankinson SE, Grodstein F. Do breast-feeding and other reproductive factors influence future risk of rheumatoid arthritis? Results from the Nurses' health study. Arthritis Rheum. 2004;50(11):3458-67.

41. Bengtsson C, Malspeis S, Orellana C, Sparks JA, Costenbader KH, Karlson EW. Association between menopausal factors and the risk of seronegative and seropositive rheumatoid arthritis: results from the Nurses' health studies. Arthritis Care Res (Hoboken). 2017;69(11):1676-84. 
42. Wolf AM, Hunter DJ, Colditz GA, Manson JE, Stampfer MJ, Corsano KA, et al. Reproducibility and validity of a self-administered physical activity questionnaire. Int J Epidemiol. 1994;23(5):991-9.

43. Sparks JA, Chang SC, Deane KD, Gan RW, Kristen Demoruelle M, Feser ML, et al. Associations of smoking and age with inflammatory joint signs among unaffected first-degree relatives of rheumatoid arthritis patients: results from studies of the etiology of rheumatoid arthritis. Arthritis Rheumatol. 2016; 68(8):1828-38.

44. de Pablo P, Romaguera D, Fisk HL, Calder PC, Quirke AM, Cartwright AJ, et al. High erythrocyte levels of the $n-6$ polyunsaturated fatty acid linoleic acid are associated with lower risk of subsequent rheumatoid arthritis in a southern European nested case-control study. Ann Rheum Dis. 2018;77(7): 981-7.

45. Zhang B, Wang P, Chen CG, He QQ, Zhuo SY, Chen YM, et al. Validation of an FFQ to estimate the intake of fatty acids using erythrocyte membrane fatty acids and multiple 3d dietary records. Public Health Nutr. 2010;13(10): 1546-52.

46. Prado MG, Iversen MD, Yu Z, Miller Kroouze R, Triedman NA, Kalia SS, et al. Effectiveness of a web-based personalized rheumatoid arthritis risk tool with or without a health educator for knowledge of RA risk factors. Arthritis Care Res (Hoboken). 2018;70(10):1421-30.

47. Sparks JA, Iversen MD, Yu Z, Triedman NA, Prado MG, Miller Kroouze R, et al. Disclosure of personalized rheumatoid arthritis risk using genetics, biomarkers, and lifestyle factors to motivate health behavior improvements:a randomized controlled trial. Arthritis Care Res (Hoboken). 2018;70(6):823-33.

Ready to submit your research? Choose BMC and benefit from:

- fast, convenient online submission

- thorough peer review by experienced researchers in your field

- rapid publication on acceptance

- support for research data, including large and complex data types

- gold Open Access which fosters wider collaboration and increased citations

- maximum visibility for your research: over $100 \mathrm{M}$ website views per year

At $\mathrm{BMC}$, research is always in progress.

Learn more biomedcentral.com/submissions 